\title{
Perihilar Bile Duct Cancer pTX TNM
}

\section{Finding $v 7$}

National Cancer Institute

\section{Source}

National Cancer Institute. Perihilar Bile Duct Cancer PTX TNM Finding V7. NCI Thesaurus.

Code C90223.

Perihilar bile duct cancer in which the primary tumor cannot be assessed. (from AJCC 7th Ed.) 